\title{
Design of a High-Temperature Superconductor Current Lead for Electric Utility SMES*
}

\author{
R. C. Niemann, Y. S. Cha, J. R. Hull \\ Argonne National Laboratory \\ Argonne, IL, USA \\ C. M. Rey, K. D. Dixon \\ The Babcock \& Wilcox Company \\ Lynchburg, VA, USA
}

\begin{abstract}
The submitted manuscript has been authored by a
contractor of the U. S. Government under contract No.

W-31-109ENG-38. Accordingly, the U. S. Government

retains a nonexctusive, royalty-free license to publish or

reproduce the published form of this contribution, ar allow

others to do so, for U. S. Government purposes.
\end{abstract}

\section{DISCLAIMER}

This report was prepared as an account of work sponsored by an agency of the United States Government. Neither the United States Government nor any agency thereof, nor any of their employees, makes any warranty, express or implied, or assumes any legal liability or responsibility for the accuracy, completeness, or usefulness of any information, apparatus, product, or process disclosed, or represents that its use would not infringe privately owned rights. Reference herein to any specific commercial product, process, or service by trade name, trademark, manufacturer, or otherwise does not necessarily constitute or imply its endorsement, recommendation, or favoring by the United States Government or any agency thereof. The views and opinions of authors expressed herein do not necessarily state or reflect those of the United States Government or any agency thereof.

For presentation at 1994 Applied Superconductivity Conference, October 16-21, 1994, Boston.

*Work partially supported by the U.S. Department of Energy, Energy Efficiency and Renewable Energy, as part of a program to develop electric power technology, under Contract W-31-109-Eng-38, and by The Babcock \& Wilcox Company, Lynchburg, VA, USA.

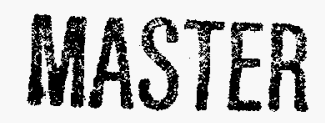




\section{DISCLAIMER}

Portions of this document may be illegible in electronic image products. Images are produced from the best available original document. 


\title{
Design of a High-Temperature Superconductor Current Lead for Electric Utility SMES
}

\author{
R. C. Niemann, Y. S. Cha, J. R. Hull \\ Argonne National Laboratory, Argonne, IL, USA \\ C. M. Rey, K. D. Dixon \\ The Babcock \& Wilcox Company, Lynchburg, VA, USA
}

\begin{abstract}
Current leads that rely on high-temperature superconductors (HTSs) to deliver power to devices operating at liquid helium temperature have the potential to reduce refrigeration requirements to levels significantly below those achievable with conventional leads. The design of HTS current leads suitable for use in near-term superconducting magnetic energy storage (SMES) is in progress. The SMES system has an $0.5 \mathrm{MWh}$ energy capacity and a discharge power of $30 \mathrm{MW}$. Lead-design considerations include safety and reliablity, electrical and thermal performance, structural integrity, manufacturability, and cost. Available details of the design, including materials, configuration, and performance predictions, are presented.
\end{abstract}

\section{INTRODUCTION}

Use of high-temperatures superconductors (HTSs) for current leads to deliver power to devices operating at liquid helium temperature, now near commercial realization, has the potential to reduce refrigeration requirements to values significantly below the theoretically best values achievable with conventional leads [1]. Such leads are particularly advantageous for superconducting magnetic energy storage (SMES) devices.

The Babcock \& Wilcox Company is engaged in a project to design, build, and demonstrate a mid-sized SMES system. The SMES has an 0.5-MW-hr energy capacity with a discharge power of $30 \mathrm{MW}$.

As part of the U.S. Department of Energy's Superconductivity Technology Program, Argonne National Laboratory and Babcock \& Wilcox are developing HTS current leads suitable for application to SMES systems.

\section{PERformance SPECIFICATIONS}

Current-lead performance specifications were developed for the SMES system. Major requirements for the lead's performance are given in Table I.

In addition to the performance requirements, the current lead assembly is to be manufacturable in a cost-effective manner.

Manuscript received October 17, 1994.

Work partially supported by the U.S. Department of Energy. Energy Efficiency and Renewable Energy, as part of a program to develop electric power technology. under Contract W-31-109-Eng-38, and by The Babcock \& Wikox Company. Lynchburg. VA, USA.
TABLE I

Major HTS Current-Lead Performance Requirements

\begin{tabular}{ll}
\hline \multicolumn{1}{c}{ Parameter } & \multicolumn{1}{c}{ Requirement } \\
\hline$I_{\text {op }}, V_{\max }, B_{\max }$ & $16 \mathrm{kA}, 5 \mathrm{kV}$, SMES + self \\
Dimensional & $0.1 \mathrm{~m} \mathrm{diax} 1 \mathrm{~m}$ long \\
Temperature & $\mathrm{T}_{\text {warm }}<60 \mathrm{~K}, \mathrm{~T}_{\text {cold }} \cong 4 \mathrm{~K}$ \\
Heat leak @ 4 $\mathrm{K}$ & $<15$ W/ead \\
$300-50 \mathrm{~K}$ cooling & Helium gas \\
$50-4 \mathrm{~K}$ cooling & Conduction \\
Structural loads & Lorentz forces, thermal contraction \\
Useful life & 25 years \\
\hline
\end{tabular}

\section{GENERAL ARRANGEMENT}

The general arrangement of the current lead is shown in Fig. 1. The major subassemblies of the current lead are the (a) conventional upper stage, (b) upper stage/middle stage transition, (c) HTS middle stage, (d) middle stage/lower stage transition, and (e) lower stage.

The current lead operates in its own separate dewar, which is electrically connected to the SMES magnet via an electric bus in an He transfer line. The advantages of this arrangement are (a) elimination of a $4 \mathrm{~K}$, high-current, high-voltage feedthrough; (b) reduced applied magnetic field at the conductor surface; and (c) less-complicated installation and maintenance. The disadvantages are increased complexity of the He transfer line to the magnet and the added heat load of the additional dewar.

\section{UPPER STAGE CURRENT LEAD}

Gas-cooled leads (GCLs) are designed to efficiently transmit current from $300 \mathrm{~K}$ to the upper/middle stage transition operating at approximately $50 \mathrm{~K}$. Helium gas at $42 \mathrm{~K}$ is supplied by a refrigerator and removes the resistive heat from the transition, as well as the resistive and conductive beat from the GCL itself. The GCL is essentially a currentcarrying heat exchanger divided into an upper and a lower portion. The residual heat not removed by helium gas exiting the top of the GCL, as well as the resistive heat traveling up from the transition, is removed by the GCL lower portion. This short segment of the lead uses a relatively large helium flow tapped from an intermediate stage of the refrigerator and returns most of the flow back to the refrigerator at a slightly elevated temperature. The balance of the flow enters the upper portion of the lead, where it returns to the refrigerator room-temperature return manifold. Performance requirements of the upper stage current lead are given in Table $\Pi$. 
TABLE II

Major Upper Stage Current Lead Performance Requirements

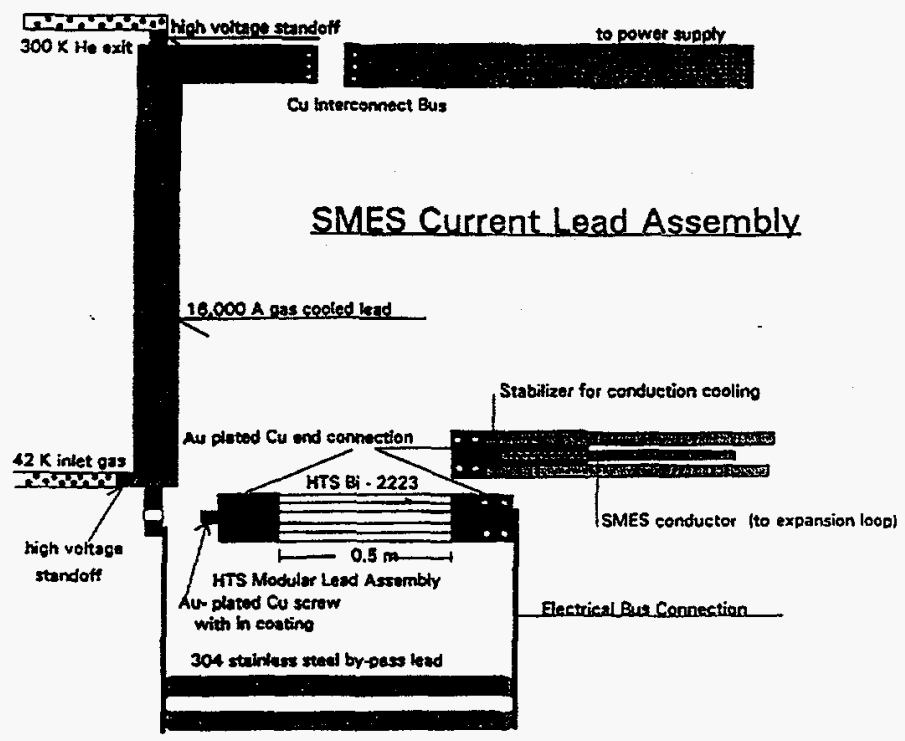

\begin{tabular}{ll}
\hline \multicolumn{1}{c}{ Parameter } & Requirement \\
\hline Current rating & $16 \mathrm{kA}$ \\
Maximum voltage during discharge & $5 \mathrm{kV}$ in gHe environment \\
Minimum bumout time & $46 \mathrm{~s}$ \\
Inlet gas temperature & $42 \mathrm{~K}$ \\
Inlet gas pressure & $0.12 \mathrm{MPa}$ \\
Maximum pressure drop across each lead & $400 \mathrm{~Pa}$ \\
\hline
\end{tabular}

\section{UPPER/MIDDLE STAGE TRANSITION}

The upper stage/middle stage transition functions include (a) electrical and structural connection, (b) current sharing control, and (c) intermediate temperature heat exchange.

Electrical and structural connection to the upper stage is by a large, fine-pitch screw thread. The mating threaded sections are made of ETP copper and are plated with nickel and gold to improve electrical and thermal conductance across the joint. The male thread is tinned with indium. Previous experience with similar screwed connections indicate that the specific electrical resistivity, based on the developed contact area of one side of the thread form, is $0.8 \mu \Omega \mathrm{cm}^{2}$ at $77 \mathrm{~K}$ [5]. Predicted resistance for this screw joint is $0.015 \mu \Omega$ at $77 \mathrm{~K}$.

Current flow through the transition can have two paths. During normal (i.e., superconducting) operation, all current flows through the female portion of the threaded connection to a circular array of current buses. To accommodate nonuniform contact resistance to the HTS elements, the buses are made of ETP copper and their geometry, area, and length are sized to control the current sharing between HTS conductor elements. Bus resistance is designed to be five or more times that of the sum of the other resistances in the conductor element current path. During the upset condition corresponding to the HTS elements being in the normal state, a fraction of the current flows through the female portion of the threaded connection to the middle stage safety lead, while the remaining fraction flows in the conductor element. The amount of current flowing through the safety lead will depend on the magnitude of the disturbance, which controls the amount of HTS that has become a normal conductor.

Helium gas at $42 \mathrm{~K}$ with a mass flow rate of $2.5 \mathrm{~g} / \mathrm{s}$ is injected at the lower end of the transition. The gas absorbs the ohmic heating of the normal metal components and the electrical connections and then enters the upper stage for its cooling. At design conditions, the temperatures of the HTS conductor element warm end and the upper stage cold end are $55 \mathrm{~K}$ and $51 \mathrm{~K}$, respectively.

Prior to testing an actual prototype current lead, the electrical characteristics of the transition will be experimentally evaluated by operation of a full-scale mock-up with current in liquid nitrogen. Areas to be studied include assembly procedure, electric resistance, and current sharing.

\section{Middle STAGE CURRENT LEAD}

The middle stage current lead functions include (a) a lowheat-leak current path to $4 \mathrm{~K}$, and (b) an electrical safety lead for protection in the event of HTS quench. The axial and 
radial cross sections of the middle stage are as shown in Figs. 2 and 3.

The middle stage incorporates 18 parallel HTS conductor elements configured in a cylindrical array. The conductor elements are supported by an internal safety lead and are connected at their ends to current collectors. Most of the middle stage is cooled by conduction from its $4 \mathrm{~K}$ end.

\section{A. HTS Conductor Elements}

The HTS material requisites include (a) high $\mathrm{J}_{\mathrm{C}}$, (b) moderate $\mathrm{J}_{\mathrm{C}}$ reduction at moderate applied fields, and (c) availability from commercial supplier. HTS conductor types considered were (a) powder-in-tube (PIT) tape composite, (b) bulk cylindrical tube, and (c) encapsulated bulk composite. A Bi-2223 PIT tape composite was selected [6-8].

Advantages of PIT composite conductors include (a) high $T_{C}$, (b) high $J_{C}$, (c) $J_{C}$ relatively insensitive to applied field at low temperature and low applied fields, (d) structurally rugged with good strain tolerance, and (e) silver sheath thermal conductivity adjustable by alloying, (f) improved interrupt condition protection capacity, and (g) greater flexibility in meeting geometric constraints. The major disadvantage is the potential high cost associated with fabricating the conductor elements. Uncertainties include piece-to-piece uniformity, end connection resistance due to resistivity of the alloyed sheath, and lifetime and reliability.

The major features of the selected conductor element are (a) PIT tape with a Bi-2223 multifilamentary core in an Ag + 3 at.\% Au sheath, (b) composite conductor of stacked PIT tapes sintered together, (c) critical current $>1100 \mathrm{~A} @ 60 \mathrm{~K}$ in $\mathrm{B}_{\text {field, }}$ (d) $4 \mathrm{~K}$ heat load $\leq 0.4 \mathrm{~W} /$ element, (e) irreversible strain limit $\geq 0.1 \%$, (f) thermal cycling results in $<4 \%$ predicted degradation in critical current, $(\mathrm{g})$ size $=0.45 \times 0.66$ x $50 \mathrm{~cm}$, and $(\mathrm{h})$ ends consisting of unalloyed silver caps.

Performance of the conductor elements is being evaluated experimentally. Measurements include conformance to specification, connection resistances, piece-to-piece uniformity, and lifetime and reliability.

\section{B. Safety Lead}

The safety lead is the core of the middle stage assembly. It provides an alternate current path, and more importantly, additional thermal mass in the event of HTS element quench. The current path is through a 304 stainless steel cylinder that is slotted to guide and mechanically support the conductor elements. The external surface is nickel- and gold-plated to improve thermal contact between the conductor elements and the safety lead. The conductor elements are fixed axially at their warm ends and are strain-relieved at their cold ends. The conductor elements are radially compressed into the slots.

The safety lead is designed to limit the HTS temperature to $<400 \mathrm{~K}$ during a quench and has a conductive heat leak to $4 \mathrm{~K}$ of $<2 \mathrm{~W}$. In the event of catastrophic failure of the HTS leads, the safety lead has a burnout time of $>100$ s so that current in the SMES magnet can be brought down to safe levels without causing further damage to the magnet and its subsystems.

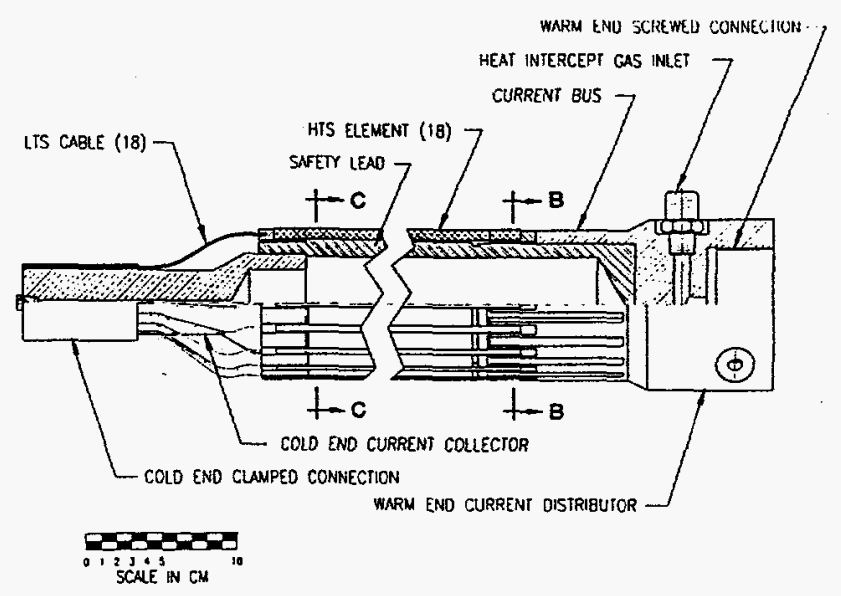

Fig. 2. Axial cross section of middle stage current lead.

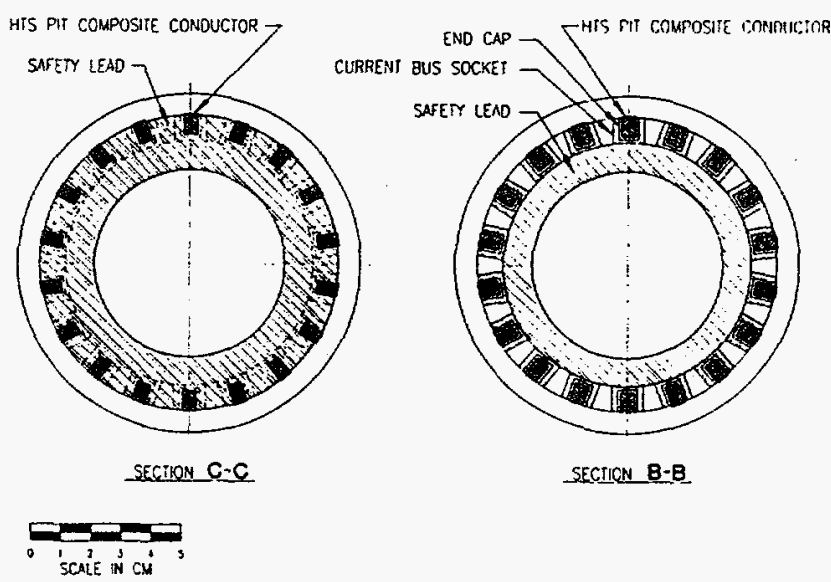

Fig. 3. Radial cross sections of middle stage current lead.

\section{MIDDLE/LOWER STAGE TRANSITION}

The middle stage/lower stage transition functions include a low electrical loss current path and HTS conductor axial strain relief.

The electrical connection to the lower stage current junction is by twisted parallel strands of low-temperature superconductor. The strands are shaped to provide axial strain relief. The $4 \mathrm{~K}$ heat load due to connection ohmic heating is $1 \mathrm{~W}$.

\section{LOWER STAGE}

The lower stage functions include (a) a low-loss electrical bus, (b) mechanical support and (c) cryogenic stability for the SMES conductor.

Electrical and structural connection to the middle/lower stage transition is by a clamp connection. The mating surfaces are made of ETP copper and are plated with nickel and gold to improve both electrical and thermal conductance across the joint. Indium foil is inserted to improve electrical and thermal contact conductance. Previous work on similar 
connections with an indium foil insert predicts an electrical contact resistance of $5 \times 10^{-9} \Omega-\mathrm{cm}^{2}$ at $4 \mathrm{~K}$ [9]. Predicted thermal resistance for the lower stage connection is $0.89 \mathrm{~K} / \mathrm{W}$ at $4 \mathrm{~K}$. The cross-sectional area and length of the lower stage copper bus are sized to provide adequate thermal conduction so as to limit the temperature rise of the middle/lower stage transition to less than $1 \mathrm{~K}$. Associated overall ohmic heating is $1.23 \mathrm{~W}$.

\section{CuRRENT LEAD ASSEMBLY}

The current lead assembly is modular in nature to facilitate installation, repair, or possible replacement with either conventional leads or improved HTS conductor elements. The upper stage will connect to the dewar with a metal gasketed flange having high voltage isolation.

\section{$\mathrm{X}$. Thermal Performance}

The purpose of using an HTS current lead rather than a conventional vapor-cooled lead in the SMES system is to reduce the required room-temperature refrigeration power. In any binary current lead design, required room-temperature refrigerator power cannot be reduced below the power necessary to cool the normal conducting part of the lead. This power depends upon the cooling concept and the cold-end temperature of the normal lead. The higher the cold-end temperature, the higher the Carnot efficiency for removing heat at the intercept temperature. The upper limit of this intercept temperature is the HTS $\mathrm{T}_{C}$ at the operating magnetic field and current. The practical upper limit of this intercept temperature is application-specific and will depend upon a number of system variables. For this application, a $50 \mathrm{~K}$ intercept was chosen. Numerical analysis of the HTS lead shows a reduction in a $4 \mathrm{~K}$ equivalent heat load by nearly onehalf that of a conventional vapor-cooled lead. This reduction translates to $>100 \mathrm{~W}$ equivalent heat load at $4 \mathrm{~K}$. Use of an HTS lead allows a reduction in the initial capital cost of the refrigeration system, in addition to a reduction of the longterm operating cost of the refrigerator. Complicated issues pertaining to the difference between (a) an HTS current lead and a smaller refrigeration system and (b) a conventional vapor-cooled lead with a larger refrigeration system, in terms of SMES system availability and reliability, have yet to be determined.

\section{CONCLUSIONS}

- An HTS current lead with a $16 \mathrm{kA}$ operating current has been designed for incorporation into a near-term, $0.5-\mathrm{MW}$-hr capacity, $30 \mathrm{MW}$ SMES system.

- The helium-gas-cooled upper stage lead operates between 300 and $50 \mathrm{~K}$. Features include multiple gas flow passages and two-stage heat exchange. The $50 \mathrm{~K}$ heat load for both leads is $196 \mathrm{~W}$.
- The conduction cooled middle stage lead operates between 50 and $4 \mathrm{~K}$. Current flow is shared by a cylindrical array of 18 parallel composite conductor elements fabricated from $\mathrm{Bi}-2223$ PIT tapes having a silver-with-gold alloy sheath. Protection is provided by a stainless steel safety lead installed in parallel to the conductor element array. The $4 \mathrm{~K}$ heat load for both leads is $11.2 \mathrm{~W}$.

- A supporting development program is underway and includes evaluations of conductor element performance and reliability, upper stage performance, connection resistances, current sharing, and manufacturing methods.

- A full scale prototype lead will be evaluated under simulated operating conditions.

\section{ACKNOWLEDGMENTS}

The authors gratefully acknowledge the manuscript preparation skills of J. A. Stephens, and the editorial contributions of C. A. Malefyt. Work at ANL was supported by the U.S. Department of Energy, Energy Efficiency and Renewable Energy, as part of a program to develop electric power technology, under Contract W-31-109-Eng-38. Work at Babcock \& Wilcox was conducted as a part of the company's SMES development program.

\section{REFERENCES}

[1] J. R. Hull, "High-temperature superconducting current leads," IEEE Trans. Appl. Supercond., vol. 3(1), pp. 869-875, 1993.

[2] K. R. Efferson, "Helium vapor cooled leads," Review of Scientific Instruments, vol. 38(12), pp. 1776-1779 (1967).

[3] R. Wesche and A. M. Fuchs, "Design of superconducting current leads," Cryogenics, vol. 34(2), p. 145 (1994).

[4] M. A. Hilal, "Optimization of current leads for superconducting systems," IEEE Trans. Magnetics, vol. MAG-13, no. 1, pp. 690-693 (1977).

[5] R. C. Niemann, Y. S. Cha, J. R. Hull, W. E. Buckles, and M. A. Daugherty, "Performance evaluations of demountable electrical connections," Advances in Cryogenic Engineering, New York: Plenum Press, 1994, vol. 39, pp. 1153-1160.

[6] H. Fujishiro, M. Ikebe, K. Noto, M. Matsukawa, T. Sasaoka, K. Nomura, J. Sato, and S. Kuma, "Low thermal conductive Bi-2223 tapes sheathed with Ag-Au alloys," IEEE Trans. Magnetics, vol. 30(4), pp. 1645-1650 (1994).

[7] T. Sasaoka, T. Umezawa, A. Nomoto, N. Tatsumi, and M. Seido, "Power current leads using Ag-sheathed high- $\mathrm{T}_{c}$ superconducting tapes," Advances in Superconductivity IV, Proc. 4th Intl. Symp. on Superconductivity (ISS '91), eds. H. Hayakawa and N. Koshizuka, New York: Springer-Verlag, 1992, pp. 621-624.

[8] S. W, Van Sciver, Y. S. Hascicek, W. D. Markiewicz, L. R. Motowidlo, D. R. Hazelton, and P. Haldar, "Strain dependence of Bi2223 tape conductors for application in high field magnets," Advances in Superconductivity V, Proc. 5th Intl. Symp. on Superconductivity (ISS '92), ed. Y. Bando, New York: Springer-Verlag, 1993, pp. $819-$ 822.

[9] S. W. Van Sciver, M. J. Nilles, and J. Pfotenhauer, "Thermal and electrical contact conductance between metals at low temperatures," Space Cryogenics Workshop, Berlin, 1984. 